\title{
Combinations of Fungicides with Phylloplane Yeasts for Improved Control of Botrytis cinerea on Geranium Seedlings
}

\author{
J. W. Buck
}

Department of Plant Pathology, University of Georgia, Georgia Station, Griffin 30223-1797.

Accepted for publication 24 September 2003.

\section{ABSTRACT}

Buck, J. W. 2004. Combinations of fungicides with phylloplane yeasts for improved control of Botrytis cinerea on geranium seedlings. Phytopathology 94:196-202.

Control of Botrytis cinerea on geranium seedlings was evaluated in treatments with phylloplane yeasts in combination with 10 fungicides used to manage Botrytis blight of ornamental plants. Rhodotorula glutinis PM4 significantly reduced the development of lesions caused by B. cinerea on geranium cotyledons; however, yeast biocontrol efficacy was highly variable between trials. Treatment with the yeast in combination with azoxystrobin or trifloxystrobin at one tenth the labeled rate $(7.5 \mu \mathrm{g}$ a.i. $\left.\mathrm{ml}^{-1}\right)$ or the full labeled rate $\left(7.5 \mu \mathrm{g}\right.$ a.i. $\left.\mathrm{ml}^{-1}\right)$ reduced lesion development, compared to treatment with the yeast or the fungicide alone. Vinclozolin at half the labeled rate or the full labeled rate $(250$ or $500 \mu \mathrm{g}$ a.i. $\mathrm{ml}^{-1}$ ), in combination with $R$. glutinis PM4, significantly reduced the development of lesions caused by an isolate of $B$. cinerea resistant to vin- clozolin. Copper hydroxide and iprodione at one-tenth the labeled rates, with or without yeast, were highly effective in limiting lesion development. Mancozeb did not increase the biocontrol efficacy of the yeast, and thiophanate-methyl negatively affected the yeast efficacy. Improved disease control was observed in treatments with vinclozolin at the labeled rate and $R$. glutinis PM4 at cell densities of $5 \times 10^{5}$ and $1 \times 10^{6}$ cells ml-1, but not $1 \times 10^{5}$ cells $\mathrm{ml}^{-1}$, on seedlings co-inoculated with $B$. cinerea in a suspension containing $1 \times 10^{5}$ conidia $\mathrm{ml}^{-1}$. Disease control improved in treatments with combinations of vinclozolin and eight other isolates of $R$. glutinis, two isolates of $R$. graminis, and two isolates of $R$. mucilaginosa. Biocontrol was not observed in treatments with two isolates of $R$. minuta. The combination of yeast and vinclozolin significantly reduced the germination of conidia of $B$. cinerea and the growth of $R$. glutinis PM4 in vitro. All combinations of $R$. glutinis PM4 with azoxystrobin, trifloxystrobin, or vinclozolin provided highly effective and consistent disease control not observed in treatments with the fungicides alone or the yeast alone.
Saprophytic yeasts have been studied as potential biological control agents for the control of various fungal pathogens, including Botrytis cinerea, Penicillium spp., and Monilinia fructicola $(6,14,21)$. Biological control yeasts have been used to manage postharvest losses due to these fungi in apples, grapes, pears, peach, sweet cherries, and citrus $(6,10,11,15,17,18,21,22)$. The yeast Candida oleophila is the active ingredient in the commercial biocontrol product Aspire, which is marketed for the control of postharvest diseases of citrus (10). Antagonistic yeasts have also been used to manage Botrytis blight of bean, cucumber, and tomato, caused by $B$. cinerea $(9,13)$.

One difficulty in using biological control agents is the need to integrate biological control into existing management plans and the requirement for consistent disease control comparable to that obtained by fungicides (12). Biological control can be enhanced by the use of mixtures of microorganisms, manipulation of the environment, or manipulation of formulations (17). In several postharvest systems, the addition of fungicides at reduced rates in combination with biocontrol yeasts has significantly enhanced disease control, compared to treatments with the yeasts alone. The combination of thiabendazole at $200 \mu \mathrm{g} \mathrm{ml}^{-1}$ with either $C$. oleophila or Pichia guilliermondii was as effective as conventional fungicide treatments in reducing citrus fruit decay caused by Penicillium spp. $(10,11)$. Pichia membranefaciens mixed with iprodione at $100 \mu \mathrm{g}$ a.i ml ${ }^{-1}$ significantly reduced the diameter of lesions caused by Rhizopus stolonifer on nectarine fruits, compared to treatment with the yeast alone (22). In two of three trials

Corresponding author: J. W. Buck; E-mail address: jbuck@griffin.uga.edu

Publication no. P-2003-1120-01R

C 2004 The American Phytopathological Society in commercial packinghouses, a combination of thiabendazole at $0.1 \mathrm{~g} \mathrm{liter}^{-1}$ and $P$. guilliermondii reduced the percentage of oranges infected by Penicillium spp., compared to treatment with the yeast alone (2). Combinations of yeasts with iprodione or thiabendazole at reduced rates $\left(20\right.$ and $15 \mu \mathrm{g}$ a.i. $\mathrm{ml}^{-1}$, respectively) significantly enhanced postharvest control of Penicillium expansum on apple and pear and M. fructicola on sweet cherry, compared to treatment with the fungicides alone at high rates (68). In all cases, the disease was significantly reduced in fruit treated with the fungicide alone at the standard high dose, compared to untreated checks $(2,6-8,10,11,22)$.

Botrytis blight of stems, leaves, and flowers of geranium is a limiting factor in commercial greenhouse production (16). Phylloplane yeasts isolated from various ornamental plants have been shown to be antagonistic to $B$. cinerea on geranium leaf disks (3). Yeasts initially identified as poor competitors have been found to significantly reduce lesion formation by $B$. cinerea when the ratio of yeast cells to conidia is $50: 1$ or $100: 1$ and nutrients are supplied at reduced levels. However, under these nutrientlimiting conditions, the biocontrol activity of some of yeast isolates varied widely in different trials (3). Phylloplane yeasts are resistant to a wide range of fungicides (5), but it is unknown whether any of these fungicides enhance biological control of $B$. cinerea on geranium by yeasts. The objectives of this work were (i) to determine whether fungicides used for managing $B$. cinerea on ornamental plants enhance disease control by the biocontrol yeast Rhodotorula glutinis PM4; (ii) to determine whether vinclozolin or thiophanate-methyl plus yeast enhance control against an isolate of $B$. cinerea resistant to both fungicides; (iii) to determine whether vinclozolin enhances control in combination with other Rhodotorula spp; and (iv) to determine the effects of thiophanate-methyl and vinclozolin on the growth of the yeast and the germination of $B$. cinerea. 


\section{MATERIALS AND METHODS}

Culture maintenance. Nine isolates of $R$. glutinis (PM4, 1C, 1D, 1F, SF1, SF2, SF3, R3, and R4) and a Ustilago sp. (isolate A5) from various ornamental plants and turfgrass were studied, having previously been screened for biocontrol activity against $B$. cinerea (3). R. glutinis PM4 and Ustilago sp. A5 were classified as "good" and "poor" antagonists of $B$. cinerea, respectively (3). Eight additional yeast isolates were obtained from the Agricultural Research Service Culture Collection, Peoria, Illinois: $R$. glutinis NRRL Y-2502 (type strain) and Y-2504, R. minuta Y-1589 (type strain) and Y-21, R. graminis Y-2474 (type strain) and Y5791, and $R$. mucilaginosa Y-2510 (type strain) and Y-27053. All yeast isolates were stored in $15 \%$ glycerol at $-70^{\circ} \mathrm{C}$. Working cultures were started on potato dextrose agar (PDA) (Difco Laboratories, Detroit) and incubated for 3 days at $26^{\circ} \mathrm{C}$ in the dark. A loopful of test yeast was suspended in distilled water, yeast cells were enumerated by hemacytometer, and the suspendsion was diluted with water to a cell density of $1 \times 10^{6}$ cells ml $^{-1}$, unless stated otherwise.

B. cinerea was isolated from a symptomatic geranium plant (3). A conidial suspension was stored in $15 \%$ glycerol at $-70^{\circ} \mathrm{C}$. Working cultures were started on PDA and incubated beneath two 34-W cool white fluorescent light bulbs ( $8 \mathrm{~h}$ of light, approximately $50 \mu \mathrm{mol} \mathrm{s}{ }^{-1} \mathrm{~m}^{-2}$, followed by $16 \mathrm{~h}$ of darkness) for 2 to 3 weeks at 22 to $24^{\circ} \mathrm{C}$. Conidia were dislodged with a glass rod from cultures flooded with 8 to $10 \mathrm{ml}$ of sterile $0.05 \%$ Tween 20 (J. T. Baker, Phillipsburg, NJ). The resulting suspension was filtered through five layers of sterile cheesecloth. The conidial suspension was centrifuged $(1,500 \times g)$, the conidia were resuspended in sterile distilled water and enumerated by hemacytometer, and the suspension was diluted with water to a conidial density of $1 \times$ $10^{5}$ conidia $\mathrm{ml}^{-1}$.

Botrytis seedling assay. Seeds of the geranium cultivar White Elite (Pelargonium $\times$ hortorum) were sown in Metro-Mix 360 (Scotts, Marysville, OH) in 72-square plug flats (TLC Polyform, Plymouth, MN), in which each square was $5.7 \times 4.0 \times 2.5 \mathrm{~cm}$. The flats were incubated under ambient light on a greenhouse bench with average day and night temperatures of 26 and $20^{\circ} \mathrm{C}$ until both cotyledons of the seedlings had fully expanded (about 12 to 14 days). Each 72-square flat was separated into 12 six-cell sections, with a single seedling per cell. Both cotyledons of each seedling were inoculated with a single $10-\mu$ drop of a test suspension of $B$. cinerea conidia $\left(1 \times 10^{5}\right.$ conidia $\left.\mathrm{ml}^{-1}\right)$ in various combinations with fungicides and biocontrol yeasts. All treatments included $25 \mathrm{mM}$ glucose and 20 -fold-diluted yeast nitrogen base (Difco) (3). Three replicate 6-cell sections per treatment were incubated in separate plastic containers $(59 \times 43 \times 15 \mathrm{~cm})$ (Sterlite, Townsend, MA) with sealed lids. An experimental unit (replicate) consisted of 12 cotyledons. Each container held 14 six-cell sections. Approximately 1 liter of tap water was added to each container to help maintain high relative humidity. Relative humidity in the containers was monitored by Watchdog data loggers (Model 150, Spectrum Technologies, Plainfield, IL) and ranged from 95 to $100 \%$. After inoculation the sealed containers were placed in an incubator at $21^{\circ} \mathrm{C}$ in the dark for $72 \mathrm{~h}$. The diameter (in millimeters) of lesions on both cotyledons of each seedling (36 cotyledons per treatment) was recorded. The seedlings were then moved to a greenhouse bench under ambient light, and seedling mortality (percent survival) was recorded after an additional 7 days (10 days after inoculation).

Fungicide screening. The following 10 fungicides registered for management of $B$. cinerea on geranium or other ornamental plants were tested to determine their effect on the biological control activity of yeasts: azoxystrobin (Heritage $50 \mathrm{WG}$, Syngenta Crop Protection, Greensboro, NC), chlorothalonil (Daconil Ultrex, Syngenta), copper hydroxide (Kocide 2000 T/N/O, Griffin, Valdosta, GA), fenhexamid (Decree, SePRO, Carmel, IN), fludioxonil (Medallion, Syngenta), iprodione (Chipco 26019, Aventis Environmental Science, Montvale, NJ), mancozeb (Dithane T/O, Dow Agrosciences, Indianapolis), thiophanatemethyl (Cleary's 3336, Cleary Chemical, Dayton, NJ), trifloxystrobin (Compass O, Olympic Horticultural Products, Bradenton, FL), and vinclozolin (Touché EG, Lesco, Strongsville, OH). Flutolanil (Contrast 70 WSP, Scotts), which is not used to manage $B$. cinerea on ornamental plants, was included as a negative control, because some of the yeast isolates are sensitive to this fungicide (5).

Each fungicide was suspended in sterile distilled water, agitated, and added to a conidial suspension $\left(1 \times 10^{5}\right.$ conidia $\left.\mathrm{ml}^{-1}\right)$ with or without a test yeast $\left(1 \times 10^{6}\right.$ cells $\left.\mathrm{ml}^{-1}\right)$. Six of the fungicides were diluted to final concentrations of one-tenth the labeled rate and the full labeled rate: azoxystrobin, 7.5 and $75.0 \mu \mathrm{g}$ a.i. $\mathrm{ml}^{-1}$; chlorothalonil, 139 and 1,390 $\mu \mathrm{g}$ a.i. $\mathrm{ml}^{-1}$; fenhexamid, 60 and $600 \mu \mathrm{g}$ a.i. $\mathrm{ml}^{-1}$; fludioxonil, 7.5 and $75.0 \mu \mathrm{g}$ a.i. $\mathrm{ml}^{-1}$; iprodione, 60 and $600 \mu \mathrm{g}$ a.i. $\mathrm{ml}^{-1}$; and trifloxystrobin, 7.5 and $75.0 \mu \mathrm{g}$ a.i. $\mathrm{ml}^{-1}$. Copper hydroxide $\left(64 \mu \mathrm{g}\right.$ a.i. $\left.\mathrm{ml}^{-1}\right)$ and mancozeb $\left(144 \mu \mathrm{g}\right.$ a.i. $\left.\mathrm{ml}^{-1}\right)$ were tested at one-tenth their labeled rates. Thiophanate-methyl and vinclozolin were tested at onetenth and one-half their labeled rates and at the full labeled rates $\left(50,250\right.$, and $500 \mu \mathrm{g}$ a.i. $\left.\mathrm{ml}^{-1}\right)$. Flutolanil was tested at a concentration of $25 \mu \mathrm{g}$ a.i. $\mathrm{ml}^{-1}$ (5). The seedlings were treated with $B$. cinerea alone, $B$. cinerea with $R$. glutinis PM4 (no fungicide), $B$. cinerea with $R$. glutinis PM4 and fungicide, and $B$. cinerea with fungicide. Ustilago sp. A5 was tested with thiophanatemethyl and vinclozolin. Each fungicide was tested at least two times at each concentration. Azoxystrobin and trifloxystrobin were tested three times.

Effect of yeast concentration and yeast isolate on fungicidebiocontrol interaction. Geranium seedlings were inoculated with R. glutinis PM4 or Ustilago sp. A5, at cell densities of $1 \times 10^{5}$, $5 \times 10^{5}$, and $1 \times 10^{6}$ cells $\mathrm{ml}^{-1}$, in combination with $B$. cinerea in a suspension containing $1 \times 10^{5}$ conidia $\mathrm{ml}^{-1}$ (3), with or without vinclozolin $\left(500 \mu \mathrm{g}\right.$ a.i. $\left.\mathrm{ml}^{-1}\right)$. The ratio of yeast cells to $B$. cinerea conidia at these concentrations was $1: 1,5: 1$, and $10: 1$. The experiment was conducted three times. Each of 16 isolates from four species of Rhodotorula was also tested for biological control activity against $B$. cinerea on geranium seedlings. The ratio of cells of each yeast isolate to $B$. cinerea conidia was $10: 1$. Seedlings were inoculated with $B$. cinerea alone or in combination with yeast, vinclozolin $\left(500 \mu \mathrm{g}\right.$ a.i. $\left.\mathrm{ml}^{-1}\right)$, or both yeast and vinclozolin. The experiment was conducted two times.

Effect of vinclozolin and thiophanate-methyl on $B$. cinerea conidial germination and yeast growth. Stock plants of the geranium cultivar White Elite were grown in Metro-Mix 360 in 11.4-liter pots and fertilized every 2 weeks with Peters 15-15-15 Geranium Special (Scotts). Ten- to 12 -week-old leaves were removed and surface-sterilized by immersion in $0.53 \% \mathrm{NaOCl}$ for $60 \mathrm{~s}$ and then in $70 \%$ ethanol for $20 \mathrm{~s}$, followed by three rinses in distilled water. Disks (12 $\mathrm{mm}$ in diameter) were cut and placed on sterilized filter paper moistened with sterile water in glass petri dishes. The disks were inoculated with $25-\mu$ l drops containing $R$. glutinis PM4 alone or in combination with conidia of $B$. cinerea, with conidia of $B$. cinerea and vinclozolin or thiophanate-methyl $\left(500 \mu \mathrm{g}\right.$ a.i. $\left.\mathrm{ml}^{-1}\right)$, or with a fungicide but without $B$. cinerea and incubated at $22^{\circ} \mathrm{C}$ in the dark. The inoculum densities were $1 \times$ $10^{6}$ yeast cells $\mathrm{ml}^{-1}$ and $1 \times 10^{5}$ conidia $\mathrm{ml}^{-1}$ in $25 \mathrm{mM}$ glucose and 20 -fold-diluted yeast nitrogen base. Yeast populations on five individual leaf disks (one inoculum droplet per disk) were determined for each treatment by leaf washing and dilution plating (4) at the start of each experiment and after $24 \mathrm{~h}$ of incubation. Each disk was placed in $1 \mathrm{ml}$ of sterile $0.05 \%$ Tween 20 solution in a $1.5-\mathrm{ml}$ microcentrifuge tube and agitated on a rotary shaker at $250 \mathrm{rpm}$ for $60 \mathrm{~min}$. Yeast colony-forming units (CFU) were quantified by serial dilution, in which each leaf disk wash solution was diluted 50-, 500-, and 1,000-fold, and four 50- $\mu$ drops 
of each dilution were placed on PDA amended with chloramphenicol (100 mg liter $\left.{ }^{-1}\right)$. Colonies were counted after 48 to $72 \mathrm{~h}$ of incubation at $26^{\circ} \mathrm{C}$ in the dark. The experiment was repeated.

Germination of $B$. cinerea conidia was determined in four separate $100-\mu$ l aliquots of all pairwise combinations of conidia, $R$. glutinis PM4, and thiophanate-methyl or vinclozolin (each at $50 \mu \mathrm{g}$ a.i. $\mathrm{ml}^{-1}$ ). All treatments included $25 \mathrm{mM}$ glucose and 20 -fold-diluted yeast nitrogen base. The tested isolate of $B$. cinerea does not germinate in distilled water without the addition of nutrients (3). Each aliquot was dispensed into a separate well in a 96 -well microtiter plate. The plates were incubated at $21^{\circ} \mathrm{C}$ for $24 \mathrm{~h}$, and at least 200 conidia per well were examined microscopically to assess germination. A conidium was considered germinated if the length of the germ tube was greater than the width of the conidium. Data were converted to percent germination. The experiment was repeated.

Statistical analysis. If there were no significant trial-by-treatment interactions, data from repeated experiments were pooled for analysis. Data were subjected to analysis of variance using the general linear model procedure (PROC GLM) of SAS (SAS Institute, Cary, NC). Means were separated by Fisher's protected least significant differences at $P=0.05$. The relationship between seedling mortality and lesion diameter was determined by the Pearson correlation procedure (PROC CORR) of SAS.

\section{RESULTS}

Screening of fungicides and yeasts in vitro and on seedlings. No lesion development was observed on seedlings inoculated

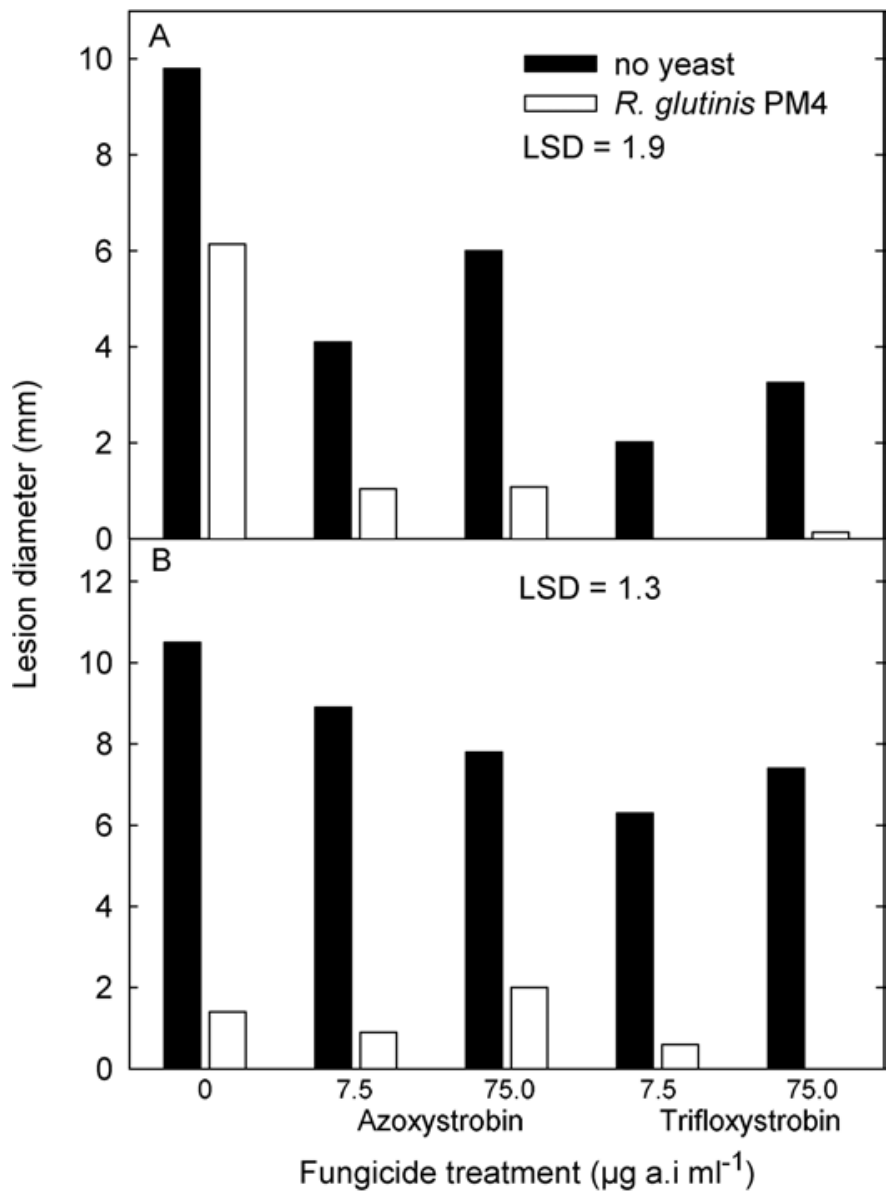

Fig. 1. Lesion development on geranium cotyledons inoculated with Botrytis cinerea alone or in combination with Rhodotorula glutinis PM4 and azoxystrobin or trifloxystrobin at rates of 7.5 and $75.0 \mu \mathrm{g}$ a.i. $\mathrm{ml}^{-1}$. Data are the average lesion diameters in three replicates of six seedlings for each treatment, in $\mathbf{A}$, a single trial and $\mathbf{B}$, combined results of two trials. with $B$. cinerea conidia and treated with chlorothalonil, fenhexamid, or fludioxonil at either one-tenth the labeled rate or the full rate, regardless of whether $R$. glutinis PM4 was added. The average lesion diameter was $9.8 \mathrm{~mm}$ in trial 1 and $10.1 \mathrm{~mm}$ in trial 2. With the addition of $R$. glutinis PM4, lesion size was significantly reduced, to $6.1 \mathrm{~mm}$ in trial $1(\mathrm{LSD}=1.9)$ and $1.2 \mathrm{~mm}$ in trial 2 (LSD = 1.1). Small lesions (less than $1 \mathrm{~mm}$ in diameter) were observed in treatments with iprodione at one-tenth the labeled rate $\left(60 \mu \mathrm{g}\right.$ a.i. $\left.\mathrm{ml}^{-1}\right)$ (average lesion diameter of $0.8 \mathrm{~mm}$ in trial 1 and $0.6 \mathrm{~mm}$ in trial 2) and copper hydroxide at one-tenth the labeled rate (average lesion diameter of $0.1 \mathrm{~mm}$ in trial 1 and $0.3 \mathrm{~mm}$ in trial 2). No lesions were observed when $R$. glutinis PM4 was included in treatment with copper hydroxide or iprodione. Treatment with mancozeb at one-tenth the labeled rate $\left(144 \mu \mathrm{g}\right.$ a.i. $\left.\mathrm{ml}^{-1}\right)$ resulted in an average lesion diameter of $5.2 \mathrm{~mm}$ in trial 1 and $9.0 \mathrm{~mm}$ in trial 2 . Treatment with mancozeb combined with $R$. glutinis PM4 resulted in an average lesion diameter of $5.8 \mathrm{~mm}$, which was not significantly different from the lesion development in treatments with mancozeb only or with yeast only in trial 1 . In trial 2 , lesion diameter in the treatment with both yeast and mancozeb $(2.9 \mathrm{~mm})$ was significantly larger than in the treatment with yeast alone $(1.2 \mathrm{~mm})$. Lesions were not observed on cotyledons that were not inoculated with $B$. cinerea.

In separate experiments, flutolanil $\left(25 \mu \mathrm{g}\right.$ a.i. $\left.\mathrm{ml}^{-1}\right)$ eliminated the biocontrol activity of $R$. glutinis PM4 (in two trials, the average lesion diameters were 15.0 and $11.0 \mathrm{~mm}$, not significantly different from lesion diameters of 15.0 and $11.0 \mathrm{~mm}$ in the controls inoculated with $B$. cinerea alone). The average lesion diameter in the flutolanil treatment without yeast was $11.7 \mathrm{~mm}$ in trial 1 $(\mathrm{LSD}=2.0)$ and $15.0 \mathrm{~mm}$ in trial $2(\mathrm{LSD}=1.2)$.

Treatment with $R$. glutinis in combination with azoxystrobin or trifloxystrobin at 7.5 or $75.0 \mu \mathrm{g}$ a.i. $\mathrm{ml}^{-1}$ significantly reduced lesion formation caused by $B$. cinerea, compared to treatment with the fungicide alone or the yeast alone in trial 1 (Fig. 1A). Lesion diameters were less than $2 \mathrm{~mm}$ in all azoxystrobin-yeast and trifloxystrobin-yeast combinations. A significant trial-bytreatment interaction $(P=0.001)$ was observed in the first two trials, which was due to the difference in average lesion sizes in the yeast $-B$. cinerea control treatment $(6.1 \mathrm{~mm}$ in trial 1 and $1.6 \mathrm{~mm}$ in trial 2). In the second and third trials (combined data shown in Fig. 1B), all yeast-fungicide treatments resulted in significantly smaller lesions than the fungicide treatments alone. No lesions were observed in treatment with $R$. glutinis plus trifloxystrobin at the full labeled rate (Fig. 1B); lesion development was significantly reduced in comparison to treatment with the yeast alone.

The isolate of $B$. cinerea used in these studies is resistant to thiophanate-methyl and vinclozolin (Table 1 and Fig. 2). In two seedling assays, vinclozolin at one-tenth the labeled rate $(50 \mu \mathrm{g}$ a.i. $\mathrm{ml}^{-1}$ ) did not significantly affect the development of lesions

TABLE 1. In vitro germination of conidia of Botrytis cinerea alone or in combinations with Rhodotorula glutinis PM4, thiophanate-methyl, and vinclozolin

\begin{tabular}{lcc}
\hline & \multicolumn{2}{c}{ Germination $(\%)^{\mathrm{b}}$} \\
\cline { 2 - 3 } Treatment $^{\mathrm{a}}$ & Trial 1 & Trial 2 \\
\hline None $($ B. cinerea conidia alone) & 72.0 & 82.2 \\
Thiophanate-methyl & 72.0 & 88.2 \\
Vinclozolin & 73.8 & 83.4 \\
$R$. glutinis PM4 & 51.3 & 46.1 \\
$R$. glutinis PM4 and thiophanate-methyl & 46.0 & 53.4 \\
$R$. glutinis PM4 and vinclozolin & 24.3 & 34.6 \\
LSD $(P=0.05)$ & 8.5 & 6.0 \\
\hline
\end{tabular}

${ }^{\text {a }}$ Fungicides were added at a concentration of $50 \mu \mathrm{g}$ a.i. $\mathrm{ml}^{-1}$. All treatments included $25 \mathrm{mM}$ glucose and 20-fold-diluted yeast nitrogen base.

${ }^{b}$ At least 200 conidia were examined microscopically to determine germination in each of four replicate wells after $24 \mathrm{~h}$ at $22^{\circ} \mathrm{C}$. 
caused by $B$. cinerea, with average lesion diameters of 10.6 and $10.8 \mathrm{~mm}$, respectively. Lesion diameters in treatment with $B$. cinerea alone were $10.1 \mathrm{~mm}$ in trial $1(\mathrm{LSD}=1.1)$ and $11.0 \mathrm{~mm}$ in trial $2(\mathrm{LSD}=2.0)$. Treatment with vinclozolin at $50 \mu \mathrm{g}$ a.i. $\mathrm{ml}^{-1}$ together with $R$. glutinis PM4 resulted in lesion diameters of 0.3 and $0.0 \mathrm{~mm}$, compared to 1.2 and $1.6 \mathrm{~mm}$ in treatment with $R$. glutinis PM4 alone in trials 1 and 2, respectively. Data from the two trials could not be combined, because of a significant trialby-treatment interaction $(P=0.001)$. Thiophanate-methyl at onetenth the labeled rate reduced biocontrol efficacy in both trials, with average lesion diameters of 3.7 and $10.0 \mathrm{~mm}$.

In two trials, vinclozolin at either half the labeled rate $(250 \mu \mathrm{g}$ a.i. $\left.\mathrm{ml}^{-1}\right)$ or the full labeled rate $\left(500 \mu \mathrm{g}\right.$ a.i. $\left.\mathrm{ml}^{-1}\right)$ in combination with $R$. glutinis PM4 significantly reduced lesion development, compared to inoculation with $B$. cinerea alone or treatment with $B$. cinerea and R. glutinis PM4 (Fig. 2). However, thiophanatemethyl (250 and $500 \mu \mathrm{g}$ a.i. $\mathrm{ml}^{-1}$ ) and a mixture of thiophanatemethyl and vinclozolin (each at $250 \mu \mathrm{g}$ a.i. $\mathrm{ml}^{-1}$ ) did not reduce lesion development, with or without $R$. glutinis PM4, and significantly increased lesion size, compared to treatment with $R$. glutinis PM4 alone. Seedling survival was negatively correlated with lesion diameter $(r=-0.717, P=0.0001)$. Seedling survival and lesion size were $15.0 \%$ and $10.6 \mathrm{~mm}$ in treatment with $B$. cinerea alone, $9.5 \%$ and $11.5 \mathrm{~mm}$ in treatment with $B$. cinerea and vinclozolin at $250 \mu \mathrm{g}$ a.i. $\mathrm{ml}^{-1}$, and $23.3 \%$ and $10.5 \mathrm{~mm}$ in treatment with $B$. cinerea and vinclozolin at $500 \mu \mathrm{g}$ a.i. $\mathrm{ml}^{-1}$; seedling survival increased and lesion diameter decreased to $48.3 \%$ and $5.2 \mathrm{~mm}, 91.1 \%$ and $1.8 \mathrm{~mm}$, and $88.3 \%$ and $1.6 \mathrm{~mm}$, respectively, in these three treatments with the addition of $R$. glutinis PM4. Treatment with vinclozolin or thiophanate-methyl at three concentrations $\left(50,250\right.$, and $500 \mu \mathrm{g}$ a.i. $\left.\mathrm{ml}^{-1}\right)$ in combination with Ustilago sp. A5 did not significantly reduce lesion formation caused by $B$. cinerea (data not shown).

Effect of yeast concentration and vinclozolin on biocontrol efficacy. Data from the three trials could not be combined for analysis, because of significant trial-by-treatment interactions. The two trials with different results in treatments with $5 \times 10^{5} \mathrm{CFU}$ $\mathrm{ml}^{-1}$ are shown in Figure 3. R. glutinis PM4 alone reduced lesion development at cell densities of $5 \times 10^{5} \mathrm{CFU} \mathrm{ml}^{-1}$ in one of three trials and $1 \times 10^{6} \mathrm{CFU} \mathrm{ml}{ }^{-1}$ in all three trials. No biocontrol was observed with a yeast concentration of $1 \times 10^{5} \mathrm{CFU} \mathrm{ml}{ }^{-1}$ in the three trials (Fig. 3). The addition of vinclozolin at $500 \mu \mathrm{g}$ a.i. $\mathrm{ml}^{-1}$

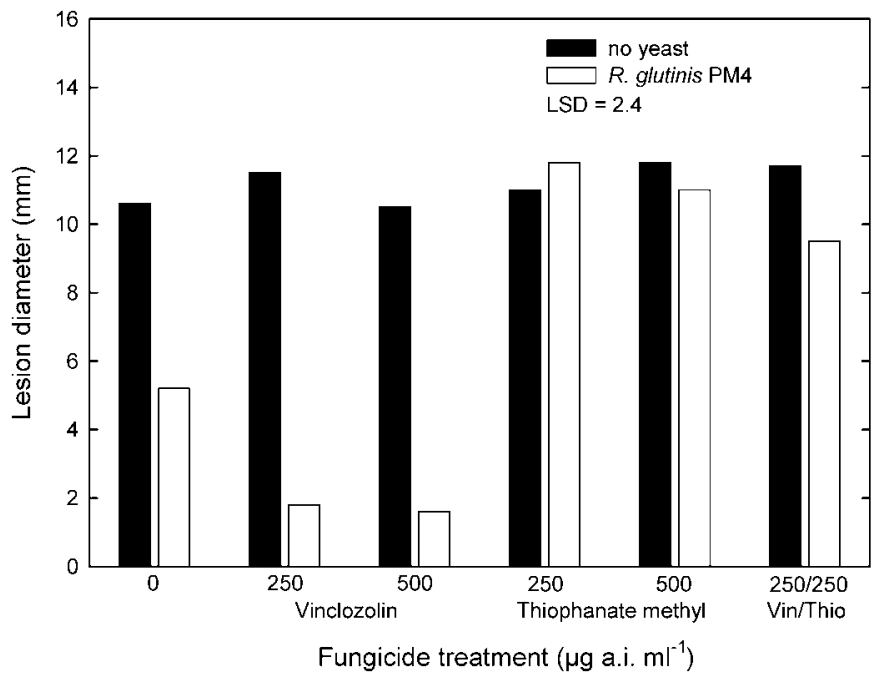

Fig. 2. Lesion development on geranium cotyledons inoculated with Botrytis cinerea alone or in combination with Rhodotorula glutinis PM4 and vinclozolin or thiophanate-methyl at half the labeled rate $\left(250 \mu \mathrm{g}\right.$ a.i. $\left.\mathrm{ml}^{-1}\right)$ and the full labeled rate $\left(500 \mu \mathrm{g}\right.$ a.i. $\left.\mathrm{ml}^{-1}\right)$. Data are the average lesion diameters in three replicates of six seedlings for each treatment, in the combined results of two trials. Vin/Thio = a mixture of vinclozolin and thiophanate-methyl, each at $250 \mu \mathrm{g}$ a.i. $\mathrm{ml}^{-1}$. significantly improved control by $R$. glutinis PM4 at cell densities of $5 \times 10^{5}$ in two of the three trials and $1 \times 10^{6} \mathrm{CFU} \mathrm{ml}^{-1}$ in all three trials (Fig. 3). Cell densities of $1 \times 10^{6}$ and $5 \times 10^{5} \mathrm{CFU} \mathrm{ml}^{-1}$ were used to attain, respectively, 10:1 and 5:1 ratios of yeast to B. cinerea. Vinclozolin did not enhance biocontrol at a $1: 1$ ratio of yeast $\left(1 \times 10^{5} \mathrm{CFU} \mathrm{ml}{ }^{-1}\right)$ to B. cinerea $($ Fig. 3). Vinclozolin did not enhance the biocontrol activity of Ustilago sp. A5 at any fungicide concentration (data not shown).

Effect of vinclozolin on biocontrol efficacy of different yeast isolates. Eleven additional isolates of four species of Rhodotorula ( $R$. glutinis, R. mucilaginosa, $R$. graminis, and $R$. minuta) were tested alone (at $1 \times 10^{6} \mathrm{CFU} \mathrm{ml}{ }^{-1}$ ) and in combination with vinclozolin at $500 \mu \mathrm{g}$ a.i. $\mathrm{ml}^{-1}$. In one trial (Fig. 4A), none of these yeast isolates reduced lesion development when used alone, but in combination with vinclozolin all but four of them (R. glutinis Y2504, R. mucilaginosa Y27053, and $R$. minuta Y1589 and Y21) significantly reduced lesion development, compared to treatments with no fungicide. In the second trial (Fig. 4B), all but five yeast isolates (R. glutinis Y2504, R. mucilaginosa Y2510 and Y27053, and $R$. minuta $\mathrm{Y} 1589$ and $\mathrm{Y} 21$ ) significantly reduced lesion development when used alone, and in combination with vinclozolin all but the $R$. minuta isolates significantly reduced lesion development, compared to treatments with no fungicide and treatment with vinclozolin alone. The $R$. minuta isolates were not effective, either alone or in combination with vinclozolin, in any tests relative to the fungicide and no-fungicide controls. For the other isolates (except $R$. graminis Y2474), the addition of vinclozolin also resulted in reduced lesion development, compared to treatment with the yeast alone, in at least one of the two trials. Treatments with vinclozolin in combination with eight isolates of $R$. glutinis obtained from turfgrass and ornamental plants-isolates 1C, 1D, and 1F (Fig. 4) and isolates SF1, SF2, SF3, R3, and R4 (data not shown)-significantly reduced lesion development, compared to treatments with yeast alone.

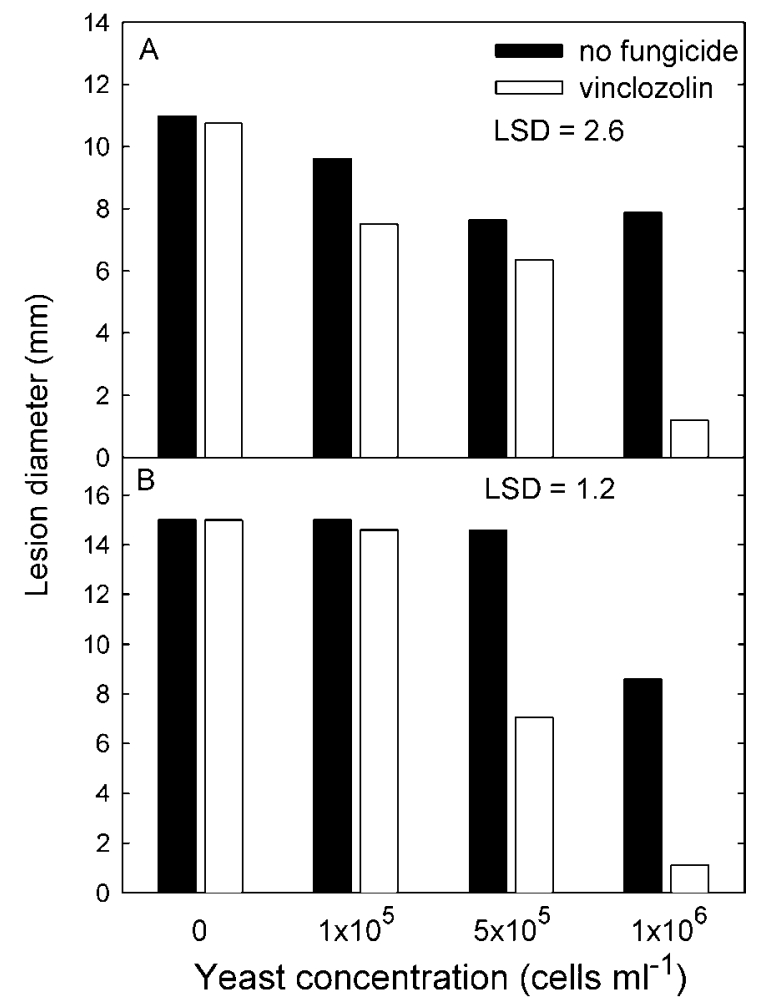

Fig. 3. Effect of the concentration of Rhodotorula glutinis PM4 and vinclozolin $\left(500 \mu \mathrm{g}\right.$ a.i. $\left.\mathrm{ml}^{-1}\right)$ on lesion development on geranium cotyledons inoculated with Botrytis cinerea at $1 \times 10^{5}$ conidia $\mathrm{ml}^{-1}$. Data are the average lesion diameters in three replicates of six seedlings for each treatment in $\mathbf{A}$, trial 1 and $\mathbf{B}$, trial 2 . 
Effect of fungicide and $R$. glutinis PM4 on germination of B. cinerea in vitro. Thiophanate-methyl and vinclozolin at a concentration of $50 \mu \mathrm{g}$ a.i. $\mathrm{ml}^{-1}$ did not reduce the germination of B. cinerea conidia (Table 1). Germination of $B$. cinerea was significantly reduced in both trials by the presence of $R$. glutinis PM4 at a 10:1 ratio of yeast to conidia, and germination was further reduced when vinclozolin was added to the yeast (Table 1 ). The germination of $B$. cinerea was not tested at the two higher concentrations of the fungicide $\left(250\right.$ and $500 \mu \mathrm{g}$ a.i. $\left.\mathrm{ml}^{-1}\right)$, because of the difficulty of seeing conidia among the fungicide particles.

Effect of fungicide and $B$. cinerea on growth of $\boldsymbol{R}$. glutinis PM4 in vitro. The growth of $R$. glutinis PM4, as determined by the increase in colony-forming units, was significantly reduced by the presence of thiophanate at $500 \mu \mathrm{g}$ a.i. $\mathrm{ml}^{-1}$ in one trial and by vinclozolin at $500 \mu \mathrm{g}$ a.i. $\mathrm{ml}^{-1}$ in both trials (Table 2). The combination of $B$. cinerea conidia and vinclozolin at $500 \mu \mathrm{g}$ a.i. $\mathrm{ml}^{-1}$ resulted in the lowest increase in yeast CFU in either trial, only a 16.1- and a 32.9-fold increase from the start of trials 1 and 2, respectively. For comparison, CFU of $R$. glutinis PM4 washed from leaf disks in the control treatments increased 92.6- and 131.5-fold over the $24-\mathrm{h}$ incubation.

\section{DISCUSSION}

Improved control of $B$. cinerea on geranium seedlings by $R$. glutinis PM4 was observed when the yeast was combined with azoxystrobin, trifloxystrobin, or vinclozolin. Of the remaining fungicides, mancozeb did not enhance biological control, and flutolanil and thiophanate-methyl negatively affected it; chlorothalonil, fenhexamid, and fludioxonil eliminated lesion formation; and copper hydroxide and iprodione reduced lesion formation by $B$. cinerea so greatly that any potential enhancement in combination with the yeast could not be observed in this system.
Improved control by vinclozolin in combination with different Rhodotorula species was somewhat unexpected, because the $B$. cinerea isolate used in this study is resistant to that fungicide. While fungicide enhancement of biological control has been observed in postharvest systems $(8,11,22)$, improved biocontrol on geranium leaves by yeast combined with fungicides has not been previously reported.

One of the primary mechanisms of the antagonism of yeasts to $B$. cinerea is nutrient competition $(13,14,19)$, and under conditions of low nutrient availability many yeasts will antagonize $B$. cinerea (3). The exact mechanism of vinclozolin-mediated enhancement of biocontrol is not known. Germination of the vinclozolin-resistant $B$. cinerea conidia was significantly reduced in the presence of vinclozolin and $R$. glutinis PM4 together,

TABLE 2. Growth of Rhodotorula glutinis PM4 on geranium leaf disks alone and in combinations with conidia of Botrytis cinerea, thiophanate-methyl, and vinclozolin

\begin{tabular}{lcc}
\hline & \multicolumn{2}{c}{$\begin{array}{c}\text { R. glutinis } \text { PM4 } \\
\left(10^{7} \mathrm{CFU} \mathrm{ml}^{-1}\right)^{\mathrm{b}}\end{array}$} \\
\cline { 2 - 3 } Treatment $^{\mathrm{a}}$ & Trial 1 & Trial 2 \\
\hline None $\left(\right.$ R. glutinis alone) $_{\text {Thiophanate-methyl }}$ & 10.43 & 12.54 \\
Vinclozolin & 7.42 & 13.43 \\
B. cinerea & 2.48 & 7.90 \\
B. cinerea and thiophanate-methyl & 7.73 & 9.49 \\
B. cinerea and vinclozolin & 4.11 & 9.01 \\
LSD $(P=0.05)$ & 1.81 & 3.35 \\
\hline
\end{tabular}

${ }^{\mathrm{a}}$ Fungicides were added at a concentration of $500 \mu \mathrm{g}$ a.i. $\mathrm{ml}^{-1}$. All treatments included $25 \mathrm{mM}$ glucose and 20 -fold-dilute yeast nitrogen base.

${ }^{b}$ Inoculum at the start of the experiments was $1.13 \times 10^{6}$ and $1.02 \times 10^{6} \mathrm{CFU}$ $\mathrm{ml}^{-1}$ in trials 1 and 2, respectively, as determined by dilution plating. Colonyforming units on five leaf disks per treatment were determined by dilution plating after $24 \mathrm{~h}$ at $22^{\circ} \mathrm{C}$.

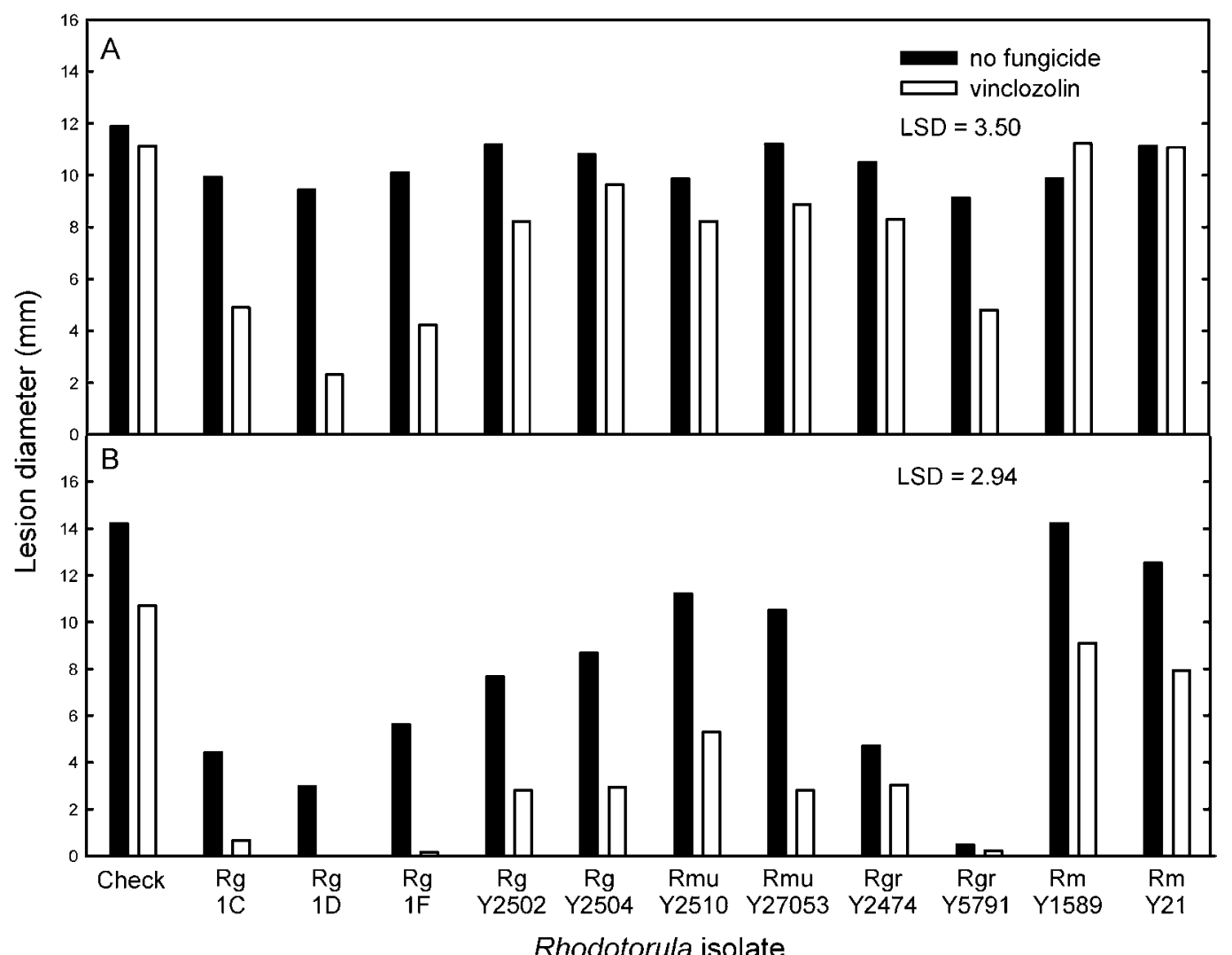

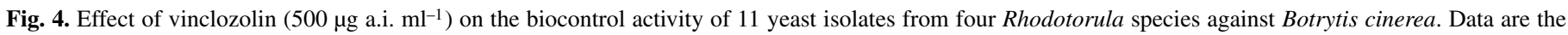

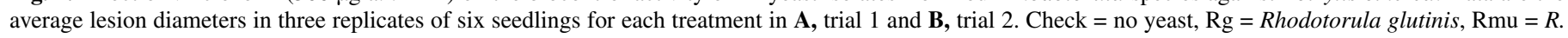
mucilaginosa, $\mathrm{Rgr}=R$. graminis, and $\mathrm{Rm}=R$. minuta . 
despite a decrease of more than $50 \%$ in yeast growth in this treatment, compared to treatments in which the fungicide was not added. The germ tubes and hyphae of the $B$. cinerea conidia appeared normal when the fungus was exposed to vinclozolin; similar observations of vinclozolin-resistant $B$. cinerea isolates were made by Yourman and Jeffers (25). Exposure to fungicides of the dicarboximide group, which includes vinclozolin, can result in a disorder of fungal cell structure and leakage of the cell contents (24). It is possible that exposure to vinclozolin caused minor damage to the conidia, which did not affect germination but reduced their ability to outcompete the yeasts for the limited nutrients available in the inoculum mixture. With fewer germinating conidia, lesion development on geranium cotyledons was significantly reduced.

Vinclozolin also could have improved biocontrol efficacy by negatively affecting other phylloplane microorganisms that compete with the yeast, and thus providing the yeast with a competitive advantage. However, the 2 -week-old cotyledons used in the present study had an almost negligible phylloplane community, as determined by leaf washing, and yeast biocontrol was improved by vinclozolin on surface-sterilized geranium leaf disks (J. W. Buck, unpublished data). This mechanism could contribute to yeast biocontrol on the phylloplane of older geranium plants, which have a more established microflora. The ability of vinclozolin to enhance biocontrol could be widespread among phylloplane yeast populations, since many of these yeasts are resistant to vinclozolin (5), and in this study biocontrol enhancement was observed in isolates of three species of Rhodotorula.

Vinclozolin applied at the labeled rate did not affect the development of lesions caused by $B$. cinerea on geranium cotyledons but did enhance disease control when combined with phylloplane yeasts. This finding differs from the fungicide-enhanced biocontrol reported in several postharvest disease systems in which the target fungi were sensitive to the fungicides incorporated into treatments with biocontrol agents $(2,6-8,10,11,22)$. Iprodione, another dicarboximide fungicide, has been found to enhance the efficacy of Cryptococcus infirmo-miniatus YY6 and C. laurentii HRA5 in the biocontrol of $M$. fructicola on cherry (7) and the efficacy of $P$. membranefaciens in the biocontrol of $R$. stolonifer on nectarine (22); however, iprodione alone, at both high and reduced rates, significantly reduced disease incidence, which indicates that the fungal isolates studied were sensitive to the fungicide $(7,22)$. Chand-Goyal and Spotts (8) tested the biocontrol ability of $C$. laurentii HRA5 and $R$. glutinis HRB6 with and without thiabendazole, a benzimidazole fungicide, applied at half rates, against a sensitive and a resistant isolate of $P$. expansum. The presence of the fungicide enhanced biocontrol of the sensitive isolate by both yeasts, but it enhanced biocontrol of the thiabendazole-resistant isolate by $C$. laurentii HRA5 only (8). Thiabendazole alone significantly reduced the incidence of disease caused by the thiabendazole-resistant $P$. expansum to $45.5 \%$, compared to $63.6 \%$ in a control group (8). The fungicide sensitivity of the target pathogen population could determine whether fungicide enhancement of yeast biocontrol is observed and to what degree.

One argument for incorporating fungicides at low concentrations (i.e., $10 \%$ of the labeled rate or less) into biocontrol mixtures is that disease control similar to that achieved by fungicides alone can be obtained with a significant reduction in fungicide use, lower levels of pesticide residues, and less potential impact on the environment $(7,11)$. Application of at-risk fungicides at reduced rates could favor rapid selection for fungicide resistance or an increase in existing resistance in target fungal populations (20). While it is assumed that fungi will not develop resistance to yeast biocontrol agents $(7,8)$, it is unknown whether a combination of yeast and fungicide will eliminate the development of fungicide resistance in a pathogen population. In the present study the combination of a yeast with several fungicides at one- tenth their labeled rates was very effective in reducing, and in some cases eliminating, disease. This reduction in disease would minimize the risk of selection for fungicide resistance. Improved control by vinclozolin at labeled rates in combination with yeast could allow direct incorporation of the biocontrol agent into an existing disease management program. Spotts et al. (23) incorporated a postharvest dip in a suspension of $C$. infirmo-miniatus with a preharvest application of iprodione at the labeled rate $\left(1.13 \mathrm{~kg} \mathrm{a.i.} \mathrm{h}^{-1}\right)$ to obtain significant improvement in the control of $M$. fructicola on sweet cherry.

Many yeasts isolated from the phylloplane of turf or ornamental plants are antagonistic toward $B$. cinerea (3). However, a wide range of biocontrol efficacy was observed among these yeasts when screened at a 10:1 ratio of yeast cells to Botrytis conidia on geranium leaf disks (3). Increasing the concentration of yeast to 100:1 significantly reduced lesion development in treatments with yeast isolates initially designated as poor antagonists. Biocontrol of $B$. cinerea by $R$. glutinis PM4 and the other yeasts evaluated in these tests was highly variable in treatments with the yeasts alone, ranging from highly effective (lesions less than $2 \mathrm{~mm}$ in diameter) to ineffective (lesions more than $10 \mathrm{~mm}$ in diameter) in different tests. This has traditionally been one of the limitations of biocontrol (1). However, R. glutinis PM4 in combination with azoxystrobin, trifloxystrobin, or vinclozolin either eliminated lesion development or limited lesion diameter to less than $2 \mathrm{~mm}$, a highly effective and consistent level of control not observed in treatments with the yeast alone. The combination of yeast at an increased concentration and the appropriate fungicide could result in more consistent biocontrol by different yeasts in the $B$. cinerea-geranium system. Combining fungicides with biocontrol yeasts in postharvest systems can provide consistency in performance and economically acceptable levels of disease control (10).

Recently it was suggested that recommendations for managing Botrytis blight of ornamental crops in greenhouses in the southeastern United States should de-emphasize the use of thiophanate-methyl, vinclozolin, and chemically related compounds, because of the low incidence of isolates still sensitive to these fungicides (25). Yeast biocontrol in conjunction with vinclozolin could allow continued use of this fungicide on ornamental crops. The enhancement of yeast biocontrol activity by vinclozolin needs to be further tested with other $B$. cinerea isolates, in scaledup greenhouse trials with natural populations of the pathogen, and on different ornamental crops.

\section{ACKNOWLEDGMENTS}

I thank Goldsmith Seeds Inc. for providing geranium seed, R. Estes for technical assistance, and D. Mueller and T. Allen for helpful comments on drafts of the manuscript.

\section{LITERATURE CITED}

1. Andrews, J. H. 1992. Biological control in the phyllosphere. Annu. Rev. Phytopathol. 30:603-635.

2. Arras, G., Scherm, B., and Migheli, Q. 2002. Improving biocontrol activity of Pichia guillermondii against post-harvest decay of oranges in commercial packing-houses by reduced concentrations of fungicides. Biocontrol Sci. Technol. 12:547-553.

3. Buck, J. W. 2002. In vitro antagonism of Botrytis cinerea by phylloplane yeasts. Can. J. Bot. 80:885-891.

4. Buck, J. W., and Andrews, J. H. 1999. Role of adhesion in the colonization of barley leaves by the yeast Rhodosporidium toruloides. Can. J. Microbiol. 45:433-440.

5. Buck, J. W., and Burpee, L. L. 2002. The effects of fungicides on the phylloplane yeast populations of creeping bentgrass. Can. J. Microbiol. 48:522-529.

6. Chand-Goyal, T., and Spotts, R. A. 1996. Control of postharvest pear diseases using natural saprophytic yeast colonists and their combination with a low dosage of thiabendazole. Postharvest Biol. Technol. 7:51-64. 
7. Chand-Goyal, T., and Spotts, R. A. 1996. Postharvest biological control of blue mold of apple and brown rot of sweet cherry by natural saprophytic yeasts alone or in combination with low doses of fungicides. Biol. Control 6:253-259.

8. Chand-Goyal, T., and Spotts, R. A. 1997. Biological control of postharvest diseases of apple and pear under semi-commercial and commercial conditions using three saprophytic yeasts. Biol. Control 10:199206.

9. Dik, A. J., Koning, G., and Köhl, J. 1999. Evaluation of microbial antagonists for biological control of Botrytis cinerea stem infection in cucumber and tomato. Eur. J. Plant Pathol. 105:115-122.

10. Droby, S., Cohen, L., Daus, A., Weiss, B., Horev, B., Chalutz, E., Hatz, H., Keren-Tzur, M., and Shachnai, A. 1998. Commercial testing of Aspire: A yeast preparation for the biological control of postharvest decay of citrus. Biol. Control 12:97-101.

11. Droby, S., Hofstein, R., Wilson, C. L., Wisniewski, M., Fridlender, B., Cohen, L., Weiss, B., Daus, A., Timar, D., and Chalutz, E. 1993. Pilot testing of Pichia guilliermondii: A biocontrol agent of postharvest diseases of citrus fruit. Biol. Control 3:47-52.

12. Droby, S., Lischinski, S., Cohen, L., Weiss, B., Daus, A., Chand-Goyal, T., Eckert, J. W., and Manulis, S. 1999. Characterization of an epiphytic yeast population of grapefruit capable of suppression of green mold decay caused by Penicillium digitatum. Biol. Control 16:27-34.

13. Elad, Y., Köhl, J., and Fokkema, N. J. 1994. Control of infection and sporulation of Botrytis cinerea on bean and tomato by saprophytic yeasts. Phytopathology 84:1193-1200.

14. Filonow, A. B., Vishniac, H. S., Anderson, J. A., and Janisiewicz, W. J. 1996. Biological control of Botrytis cinerea in apple by yeasts from various habitats and their putative mechanisms of antagonism. Biol. Control 7:212-220.

15. Guinebretiere, M. H., Nguyen-The, C., Morrison, N., and Nicot, P. 2000. Isolation and characterization of antagonists for the biocontrol of the postharvest wound pathogen Botrytis cinerea on strawberry fruits. J. Food Prot. 63:386-394.

16. Hausbeck, M. K. 1993. Botrytis blight. Pages 223-228 in: Geraniums IV. J. W. White, ed. Ball Publishing, Geneva, IL.

17. Janisiewicz, W. J., and Korsten, L. 2002. Biological control of postharvest diseases of fruits. Annu. Rev. Phytopathol. 40:411-441.

18. Janisiewicz, W. J., Peterson, D. L., and Bors, R. 1994. Control of storage decay of apples with Sporobolomyces roseus. Plant Dis. 78:466-470.

19. Janisiewicz, W. J., Tworkoski, T. J., and Sharer, C. 2000. Characterizing the mechanism of biological control of postharvest diseases on fruits with a simple method to study competition for nutrients. Phytopathology 90:1196-1200.

20. Kable, P. F., and Jeffery, H. 1980. Selection for tolerance in organisms exposed to sprays of biocide mixtures: A theoretical model. Phytopathology 70:8-12.

21. McLaughlin, R. J., Wilson, C. L., Droby, S., Ben-Arie, R., and Chalutz, E. 1992. Biological control of postharvest diseases of grape, peach, and apple with the yeasts Kloeckera apiculata and Candida guilliermondii. Plant Dis. 76:470-473.

22. Qing, F., and Shiping, T. 2000. Postharvest biological control of Rhizopus rot of nectarine fruits by Pichia membranefaciens. Plant Dis. 84:1212-1216.

23. Spotts, R. A., Cervantes, L. A., Facteau, T. J., and Chand-Goyal, T. 1998. Control of brown rot and blue mold of sweet cherry with preharvest iprodione, postharvest Cryptococcus infirmo-miniatus, and modified atmosphere packaging. Plant Dis. 82:1158-1160.

24. Uesugi, Y. 1998. Fungicide classes: Chemistry, uses and mode of action. Pages 23-56 in: Fungicidal Activity: Chemical and Biological Approaches to Plant Protection. D. Hutson and J. Miyamoto, eds. John Wiley \& Sons, New York.

25. Yourman, L. F., and Jeffers, S. N. 1999. Resistance to benzimidazole and dicarboximide fungicides in greenhouse isolates of Botrytis cinerea. Plant Dis. 83:569-575. 